\title{
English as a Tool to Prevent Bullying and Encourage Equalities: The KiVa Project
}

\author{
María de la Hoz Martínez Jiménez \\ TALIS Research Group, University of Valencia, Valencia, Spain
}

\author{
María Alcantud Díaz \\ TALIS research group, Department of Language and Literature Teaching, University of Valencia, Valencia, Spain
}

\begin{abstract}
Through the combination of the KiVa project and the English language beyond its formal academic aspects, this work aims to achieve an efficient antibullying program that fits the students' needs. The main objective of this research is to prevent bullying, to encourage equalities and to ensure that bullying victims can count on the support of the class group to feel more confident about themselves and to not be afraid. To carry out all this, we suggest using English as students' $L 2$ in order that it serves as a tool to prevent bullying. Moreover, English is chosen as the subject since it is a neutral common language for all the students, and leads to an environment of equality in the classroom and to the suppression of group roles. Some methodological strategies were implemented in Primary and Secondary to compare the results obtained, to reach the goals and to improve the use of English language through communication.
\end{abstract}

Index Terms - anti-bullying program, peer group support, KiVa project, English language, self-esteem, equality

\section{INTRODUCTION}

Bullying is a current problem in educational settings worldwide and approximately between 2 and $6 \%$ of schoolchildren can be classified as bully-victims (Haynie et al., 2001), which shows the necessity of effective antibullying intervention programs. Hence, following this line, a combination of the KiVa Project (focused on the benefits that the group class attitude owns to face bullying problems) and the English language, as an element that could generate equality in the classroom, could be a useful tool to cease bullying problems in school.

This work is a further step in the investigation and implementation that started in 2015 in Primary Education and continued in 2017 in Secondary Education. Therefore, the main purpose of this work is threefold: first, to prevent bullying in the classroom. Second, to use English as a Foreign Language classes to carry out the project since it fits the search for a neutral common ground for all the students, and to work on clothing vocabulary, present simple and continuous tenses, oral and written communication. And third, to make a comparison between the results obtained in Primary and Secondary in order to replicate, correct and improve the KiVa project.

The justification for the choice of this language is due to its importance worldwide since there are about 375 million English-as-a-first-language speakers and 750 million English-as-a-second-language speakers. According to what has been written previously, this work suggests that as English as a Second Language is not the students' mother tongue, all of them feel some degrees of insecurity speaking English. So, bullies, victims and the whole class will have to face the same situation on equal terms. All in all, efficient anti-bullying programs require modifications and renovations in the school organization and culture. Such changes will take place principally through the teachers, who will really learn the significance of bullying when they carry out an anti-bullying program in their classrooms and reflect on it.

\section{THEORETICAL FRAMEWORK}

This section is organized in two main nuclei. The first one consists of an explanation of the KiVa project, its origin and its methodology. Then, we will see the importance of using discussion as a useful tool to solve bulling problems. I will afterwards explain how relevant it is to foster teacher's motivation when implementing an anti-bullying program. Moreover, I will depict the positive balance that numerous studies give to the KiVa project regarding its effectiveness in order to make clear that this program is worth it.

The second nucleus that will be addressed in this section is about the use of the English language to promote equality in the classroom through the English as a Medium of Instruction (EMI) methodology. Thus, I will write about the English language and its benefits beyond its formal academic aspects. I will show how this fact would allow English to play a crucial role when removing and preventing bullying problems in the classroom and to create anti-bullying attitudes among students. Finally, the most common kinds of bystanders will be exposed to try to find a solution in order to avoid all types of roles in the classroom so as to achieve an atmosphere of equality (an aim that can be reached 
through the use of the English language in class). It is precisely such atmosphere the one which the KiVa program looks for in order to be effectively implemented.

\section{A. The KiVa Antibullying Program}

The KiVa anti-bullying program is well grounded in research, that is to say, currently there are many studies about how to improve situations of bullying in the classroom. First of all, it is important to understand the concept of bullying and the effects it produces on people. Furthermore, it is relevant to take into account that bullying has become unfortunately a buzz issue due to the fact than it is on daily news more and more often. It is "a serious personal, social and academic problem, which affects a large number of pupils and causes widespread concern owing to its rapid spread, which is why it needs to be combated immediately" (Mavroudis and Bournelli, 2016, pp. 1-2).

Bullying is defined as a repeated aggressive behaviour that hurts you or makes you feel unhappy, uncomfortable or scared (Gordon and Spilsbury, 2014) and its targets/victims suffer psychosocial problems such as depression, anxiety, and peer rejection (Card and Hodges, 2008; Hawker and Boulton, 2000). Besides the targets, bullying constitutes a risk for a healthy development of the perpetrators (Sourander et al., 2007) as well as for bystanders merely witnessing victimization (Rivers et al., 2009). This shows that it is necessary to have an efficient action plan that prevents bullying and shows teachers, students and other educational staff how to act in bullying situations.

The fact that school attendance is compulsory turns it into a place where bullied students cannot escape their oppressors while bullies are socially rewarded by those peers who, as Salmivally states, "join their behaviour or just reinforce it by verbal or nonverbal signals" (Salmivally, 2010, pp. 112-120). From the point of view of this work and in accordance with Wentzel, "the quality of peer relations, especially emotional support (or lack of it) from peers, has significant consequences for school motivation, engagement, and achievement" (Wentzel, 2009, pp. 536-538), it can be said that group problems need group solutions. In addition, in recent years, there has been a growth of interventions focused on working with the peer group (Del Barrio et al., 2011).

Therefore, KiVa project has been chosen as the main reference for this work since, combined with the many benefits of English as a Second Language, constitutes an action-prevention plan against bullying that can prove to be very beneficial to education. In turn, Leganés highlights the importance of carrying out prevention-oriented interventions to eradicate abusive behaviour before it appears (Leganés, 2012).

\section{a. Origins of the Program}

The KiVa project was developed and carried out at the University of Turku, in collaboration with the Department of Psychology and the Centre for Learning Research by order of the Finnish Ministry of Education in 2006. Its name is an acronym that stands for Kiusaamista Vastaan, that means "against bullying" in Finnish, and the adjective kiva also means "nice" in the same language. This program considers bullying as a group phenomenon and includes universal actions to prevent bullying and indicated actions to address individual cases of bullying. More specifically, the program is based on the idea that bystanders often contribute to the maintenance of bullying by assisting and reinforcing the bully (Salmivalli, Voeten and Poskiparta, 2011), which provides bullies with the power and the status that they are seeking (Salmivalli, 2010).

Salmivalli et al. explain the most common kinds of bystanders: "there are assistants (those who physically help the bully), reinforcers (those who incite the bully), outsiders (those who do nothing) and defenders (those who confront the bully and help the victim)." (Salmivalli, 1996, pp. 1-15). In order to avoid all kinds of roles in the classroom (bullies, victims and bystanders) and to complement the KiVa project it is necessary to create a neutral learning environment in which all the participants feel and experience some kind of weaknesses. As it has been mentioned previously, the proposal depicted in the present work is that English as a Second Language classes might work at that environment.

Using such a combination of the KiVa project and the English as a Second Language classes, it is expected that victims will be less affected and anxious and more motivated. Additionally, they will have higher self-esteem, and they will be less rejected by their peers. In turn, that bullies will be expected to reduce their motivation to bully, and understand that we are all equal and violence is not the way to happiness. Regarding bystanders, they will act with no fear and provide support to victims while understanding that they have played and are playing a central role in maintaining bullying cases. In fact, sometimes for bullying targets "the most painful experience involved in being bullied is not necessarily the attacks by mean kids, but the perception that the whole group is against them" (Sainio et al., 2011, pp. 144-151).

\section{b. Operating Mode}

With regard to the way the KiVa project works, it can be said that it includes lessons and topics which involve discussion, group/team work, short films related to bullying and role-play activities. More specifically, the more relevant themes of the lessons are the following ones, which will be worked on and adapted to the students' needs thanks to the different activities proposed in the Methodology section:

- Let's get to know each other

- Emotions

- Our class -everyone is included!

- Difference is a richness

- There is no bullying in a KiVa school

- We won't join in bullying 
- The victim needs your support

- I will not be bullied!

- Literature lesson

- KiVa contract' (Herkama, 2012, pp. 16-18).

As it can be observed, the contents of the lessons are based on different values such as the importance of respect, emotions, group pressure, bullying and its consequences and mechanisms and so on, which are very important to be developed at school in order to contribute positively to the students' behaviour building.

Moreover, KiVa uses virtual learning environments (anti-bullying computer games for younger children and an online environment named 'KiVa Street' for older students) in order to motivate students and enhance their learning process. For instance, computer games are composed of five levels, each one of them based on three components: 'I Know', where students reinforce and increase their bullying knowledge; 'I Can', where students acquire new useful skills to act in bullying situations; and 'I Do', where students are encouraged to use the knowledge and skills they have acquired in real-life situations. Furthermore, there is a mailbox that students can use to send e-mails informing about bullying situations that some classmate or they themselves suffer. It is very useful if we consider that "'most targets of bullying still do not report their harassment at school or at home, thus hindering any kind of effective intervention" (Salmivalli and Poskiparta, 2012, pp.41-53).

Regarding discussions, they can be individual or in group and they involve victims and bullies. In addition, the teacher arranges a meeting with some ( 2 or 4 ) classmates -who have been identified as friendly classmates by the victims- to encourage them to support the victims. Thanks to activities like these and according to Kärnä et al., 'increases the empathy towards victimized peers as well as self-efficacy to support them and reduces the bystander's likelihood of reinforcing bullies' mean acts' (Kärnä et al., 2011, pp. 405-411). And that is one of the things that this work looks for, that bystanders are able to put themselves in the place of their victims to comprehend their thoughts and their feelings; that they do not give bullies what they want: social recognition for their actions.

\section{B. The English Language beyond Its Formal Academic Aspects}

English is one of the most widely spoken languages and it is used all over the world. It is a language that is commonly learnt by people who have a L1 (first language) other than English. So, English language does not only belong to its native speakers but also to the entire world. According to the New York Times, ' 400 million people speak English as a first language and another 300 million to 500 million as a fluent second language' (Mydans, 2007, p.55). So, it can be affirmed that the world seems to need a common language, something that serves as an intercultural link, a meeting point, and allowed all its inhabitants to communicate among them on equal terms. The same occurs in the classroom: all the students need a language that allowed them to communicate among them on equal terms. That is, to get in touch without feeling different because of speaking their L2 better or worse. Hence, they need a language different from their mother tongue; a language such as English, which was able to generate an environment of equality in the classroom, without bullies or victims; without victors or losers.

All this leads us to think about the following question: what would happen if some students spoke English better than the rest? (Because this is something that uses to happen in the classroom). Then, it would be appropriate to provide feedback to those pupils who find English language hard. This would be done to encourage and motivate them to continue working in that language. Moreover, they could be provided with resources and extra work in order to reinforce their English language.

Regarding the benefits of English lessons, according to the European Commission (2009) it can be said that they lead to increased memory capacities, since 'learning English allows the brain to keep information in it for longer durations while thinking processes are activated'; they also increase mental flexibility because English learning 'allows a person to use differing avenues for thought', keeping the brain active and flexible; it is also profitable for increased problemsolving abilities such as 'abstract thinking skills, concept formation, creative hypothesis formulation, strengthened capacity to identify, understand and solve problems and the ability to focus on a task by filtering out distractions'. English lessons are also useful to enhance comprehension on how language works and is used because English students 'are able to better read and interpret social situations'. Moreover, it 'prevents the deterioration of brain functioning over time' and it leads to an increased ability in digital literacy, since 'because of these quickened mental abilities individuals which are multilingual have a noticeable ability to stay up to date with modern technologies' (pp.1-17).

\section{English Language for Long Life Learning: English as a Medium of Instruction (EMI)}

With all these benefits of English language it is not difficult to assume that it is worth learning it from a very early age (Kristo, 2010). In fact, its advantages for living are, for instance, that it makes easier and more enjoyable travelling and interacting with people of different countries. In addition, it gives us access to more current and complete information since most studies, scientific texts and Internet files and documents are written in English. English language also shows different ways of thinking and a wide range of interesting cultures and lifestyles. So, new people can be met and their customs understood. Thus, giving the opportunity to see yourself through different eyes, and perhaps discovering new aspects of yourself or your culture on which you had not reflected before.

Moreover, studies such as those carried out by Pavesi et al. (2001) state that "incidental language learning -the kind of learning which occurs when the learners' attention is focused on something different from what is being taught- is 
very effective, deep and long-lasting. It positively complements the intentional language learning which typically occurs in the more traditional language classroom" (Pavesi et al., 2001, pp. 9-10)

This makes us think about what kind of English learning our students need. So, as stated in the objectives at the beginning of this work, students need an incidental English language learning that does not try to replace traditional language teaching but complements it. That is an English language learning that goes beyond its formal academic aspects and makes students think critically and share ideas and opinions -also against aggressive behaviour- at the same time they practice their speaking skills, which are on equal terms for all of them since English language is not students' L1.

Hence, this work proposes taking advantage of English language by using it as a learning and teaching tool in order to create anti-bullying-attitudes among students by reflecting, discussing, sharing ideas and feelings. So, I followed a methodological approach based on English as a Medium of instruction (EMI). This phenomenon has very important implications for the education of young people in non-anglophone countries. Unlike CLIL, where both the language and content is the focus of learning, EMI concentrates on the content with the use of the language as the medium of instruction.

Therefore, EMI proposes the use of the English language to teach academic subjects in countries where the L1 is not English. In this way, this language becomes a useful tool of instruction and classroom management by using specific teaching strategies (Dearden, 2015). It is becoming increasingly important since "there appears to be a fast-moving worldwide shift, from English being taught as a foreign language (EFL) to English being the medium of instruction (EMI) for academic subjects". (Dearden, 2015, p.4). Hence, for this work, the English language is intended to play a crucial role in the classroom generating empathy and respect for others while students develop anti-bullying awareness. The following section, will be, thus, devoted to depicting the methodology proposed.

\section{METHODOLOGY}

The methodology implemented in this didactic experience was put into practice for the first time in the course 2015/16 in Primary 5, during the Practicum period of the Teaching Degree. Some very clarifying results such as the decrease in the number of harassment situations were obtained. Furthermore, "students were able to feel the warmth of their peers and a sense of togetherness was created beyond what the academic hours have allowed" (Martínez, M., 2016). Now a similar implementation was put into practice in Secondary 1 by replicating the method already proved in that course. That is, using the same materials as in Primary Education and looking for new ones (adapted to the students' age). We have selected this course because "late childhood is a period when bullying tends to increase and peers take on increased importance in promoting children's social development and fulfilling their need for acceptance" (Salmivalli et al., 2016).

Hence, this section is divided into three parts. First, it is described the context where the implementation of the proposal of this work was carried out. Then, the experience in Secondary Education will be displayed through different activities designed and adapted to teenager students. As mentioned, the further implementation will follow the same line of the one executed in Primary Education in the study of Martínez, 2016. Moreover, a comparison between these two educational stages will be done. Finally, some strategies for data collection and its evaluation will be shown and discussed.

In this internship, I chose a private school. The aim was to know a different context, since I had never been in a private school before and I did not know how it worked. Moreover, I wanted to know other students, teachers and methodologies different from what I had seen so far in other schools. This has allowed me to train and enrich myself not only as a professional but also as a person.

\section{A. Context and Design}

Hereafter, an explanation of the place and the context in which the investigation was carried out would be comprised. The educational centre is located in a neighbourhood of middle-high socioeconomic level. The duration of the Practicum period was two months, from January 30th to March 31st. During that time, I was in different classes of ESO and Bachiller for the English language classes. Moreover, spending more time in ESO 1 I could observe the behaviour and the different roles of students in that class, in which this work was applied.

One aspect that caught my attention during the Practicum was the school need of having an effective anti-bullying program since although it had taken on a mediator, there was discrimination in the classroom (we will focus on ESO 1 class composed by 27 students) and there were assumed leadership roles (clearly differentiated). The class needed a proper and innovative anti-bullying program that at the same time made students practice and reinforce the English language (a subject in which they had many weaknesses in).

\section{B. Objectives of the Implementation}

Hereafter comprise an explanation of the different goals expected for each activity that I put into practice. They are related to both the improvement of the students' English language level and the prevention-reduction of bullying effects. 
- Session 1 (Storytelling and group discussion): To improve students' listening skills while their critical thinking emerges. To prevent bullying and reduce victimization by means of fostering an atmosphere of equality, respect and well-being in the classroom through communication in English.

- Session 2 (running dictation): To improve the students' competence of the English language and their written comprehension (misspellings, verbs conjugated badly, articles and prepositions not used correctly and so on). Also, it is aimed at working on clothing vocabulary, present simple and continuous tenses. Moreover, it is pretended to foster cooperative learning.

- Session 3 (identity text): to increase students' self-confidence and to achieve a classroom atmosphere where inclusion and equality prevail. Moreover, it is aimed at working on adjectives.

- Session 4 (hearts on the back): to work on emotions and inclusion; to raise awareness about the importance of supporting victims; and to increase victims' self-confidence. Furthermore, it is also aimed at working on adjectives.

\section{Implementation}

During the month of February this work was organized by carrying out a research about the KiVa project along with the benefits of English language in the classroom, and an observation of students' characteristics and their relationships as a group. After that, the students were asked to complete the pre-test during the last week of February. Then I worked on the chosen text and the adapted activities for the students, from the last week of February to March, and some talks/tutoring took place between the teacher and the students in this period of time. Finally, the students were asked to complete the post-test (same test than the pre-test) during the last week of March and from that day, some conclusions about the effectiveness of this proposal were drawn.

In the practice period, the didactic intervention was developed through some activities inspired in the KiVa project, adapted to the students' needs. Moreover, a set of tutorials were performed. Firstly, with the affected students and then, with the whole class, following the steps of the Kiva project.

- Session 1 (Storytelling and group discussion): we read 'Baseball Saved Us' (Mochizuki, K., 1993) to the students, which were sited in circle to promote an atmosphere of discussion. The book was about bullying during the Second World War. It is important to spend time reflecting while reading, not only at the end of the book, to make the reading richer. So, students could discuss personal experiences and being in others' shoes. Furthermore, communicative approach was developed while fostering the use of the English language.

- Session 2 (running dictation): this activity was selected due to its usefulness to improve the students' competence of the English language. The activity is based on text which contains values such as equality, respect and empathy and that incorporates the target grammar. Moreover, it emphasized the idea that we are all necessary in a group, which was discussed later in a further discussion.

- Session 3 (identity text): This activity is useful to meet each other beyond what you can discover about him/her in class; to remove tags and discover lots of things you did not know; and to foster the idea that we are all good at something. It consisted of creating a mural for the whole class where students had to hang human silhouettes made of paper. Each student had to create a human silhouette and write good things about himself. Hence, this activity created opportunities to bring out the inner voice of students and to make visible what was invisible of them.

- Session 4 (hearts on the back): all students had to write in some post-its something good and stick them on the heart of all their classmates so, all the students had a heart stuck on their back. In this way, students received beautiful words from their peers and their self-confidence could increase.

\section{Strategies for Data Collection and Its Evaluation}

Data were collected through a questionnaire that students filled in twice, once before the implementation of our proposal and then after doing the different activities and talks mentioned above in order to see the point we started the implementation of this work from (students' conceptions about bullying, current situation of bullying in the classroom, and behaviour that pupils would follow in the face of a situation of this type); and to check if the implementation had been a success 


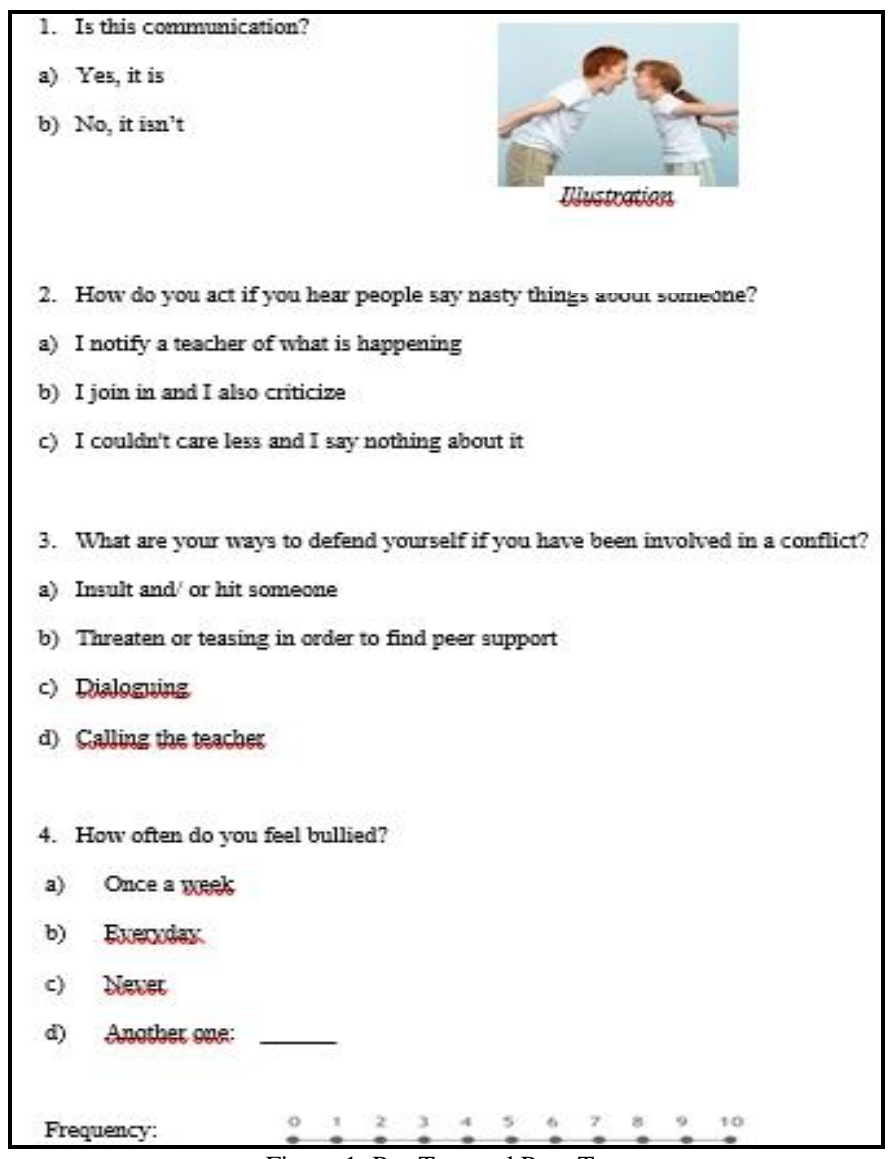

Figure 1. Pre-Test and Post-Test

$$
\begin{aligned}
& \text { a) Yes, it is } \\
& \text { b) No, it isn't }
\end{aligned}
$$

5. Is this bullying or not?

6. Is it worthwhile to report bullying to adults?

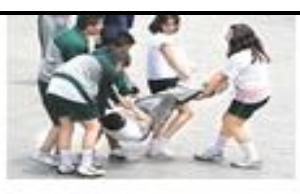

Iliustration

a) Yes, in order that they help us

b) No, because If I do it, I will be a snitch

7. Is she a bullying victim?

a) Yes, she is

b) No, she isn't

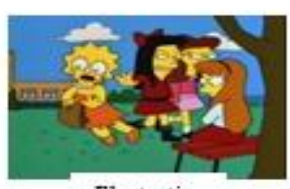

Bustration

8. Victims of bullying are always weird people
a) True

b) False

9. In a case of bullying (as bystander) I feel ...

a) Afraid

b) Entertained

c) Brave and willing to help

10. If I suffered bullying, I would like to feel the support of....

a) Beers (class group)

b) Teacher

c) Psuchologiat.

Figure 2. Pre-Test and Post-Test 
Furthermore, the data from these tests (pre-test and post-test) were evaluated quantitatively. The aim was to observe a reduction in the number of victims in order to demonstrate the efficacy of this didactic implementation proposal. In addition, it is important for this project to be an effective prevention tool so that data were also evaluated qualitatively by valuating students' interpretations, judgments, motivations, interests and needs in order to comprehend what they need and to solve situations through action and reflection. Moreover, the data were also gathered by means of direct observation through a logbook.

\section{RESULTS AND DISCUSSION}

\section{A. Direct Observation}

Regarding running dictation, the students had fun and worked the Total Physical Response (TPR) method, which is very useful to collaborate with the language learning, so then they were more relaxed for the discussion. In the study carried out by Martínez, 2016 in Primary 5, students were open and comprehensive at all times and they participated in an active way in the discussion providing ideas such as: "without the aid of all the members of the group we would not have completed the dictation" (Martínez, 2016). While in this study, the students of ESO 1 also showed an active attitude since it was a new activity for them. In the discussion, students mentioned ideas such as "it is important to distribute alright the roles within the group and trust that we are all capable of doing our mission well". As it can be observed, in both cases some values such as the importance of everybody, teamwork, empathy, patience and respect appeared. Therefore, it can be stated that the goals proposed for this activity were achieved and also the English language grammar, vocabulary, writing and communicational skills were successfully worked on.

Concerning the hearts activity, it was useful to identify the roles that the different class members had got. Regarding ESO 1, some post-its included adjectives such as "different", so we took the opportunity to explain that this adjective was not something bad but that their peers had seen it as something positive. In general terms, in both courses the objectives were accomplished because this activity increased students' self-esteem and developed their communicative skills. Furthermore, the victims felt they had their peers' support and the bullies realized their good qualities, which was profitable for them to love themselves more and to stop behaving aggressively towards others for this reason.

With regard to the identity text, thanks to this activity the students knew each other better and discovered lots of new things they did not know about their peers, while at the same time, they removed pre-established labels that they had put at the beginning of the course. In addition, their self-confidence increased and the English language was used as a communicational tool. Furthermore, the students had the opportunity to reflect about who they are, which was difficult at the beginning because it is something that we are not used to do.

Finally, as far as the storytelling activity is concerned, critical thinking was present during the entire activity and in the following debate. Moreover, the whole activity was carried out in English so, a communicative approach was implemented. At the same time, students were able to detect traditional symbols from other cultures so, their intercultural awareness increased.

\section{B. Pre-test and Post-test}

The two tests taken before and after the implementation of the proposal of this work led to different results. On the one hand, in the study carried out in Primary 5 by Martínez in 2016, in the pre-test, 4 out of 27 students of the class claimed to have suffered/be suffering bullying very frequently (7-10 times) (Martínez, 2016). On the other hand, the pre-tests conducted in ESO 1 revealed that two students of the class were suffering bullying at that time (one of them with high frequency -everyday- and the other one once a week). A third student had experienced bullying during his/her childhood. All this was happening in two classes seemingly quiet and with a good atmosphere, where it had previously been explained what bullying was so that students did not think that it was a solitary conflict, anger or dispute.

One of the most interesting aspects is that in the ninth question of the pre-test, the majority of the pupils answered that they felt brave and willing to help when facing a conflict of bullying, in the case of Primary 5 (Martínez, 2016). While in ESO 1, a large number of students stated that they felt frightened each time they witnessed a bullying conflict. It is here where the proposal of this work has impinged on by promoting a students' change of attitude thanks to the work on feelings such as bravery, and making them aware of the great importance of their behaviour when they witness a case of bullying. Another important aspect to highlight, which is very relevant for this work, is the answer given by the students to question number ten. In both cases (Primary 5 and ESO 1) the importance of feeling peer support when in a situation of bullying is shown in this work, as indicated by the KiVa project. Tables 1 and 2 show the results obtained in the realization of the pre-test in both schools. 
TABLE I.

Chart With The Results Of The Pre-Test In Primary 5 (Martínez, 2016)

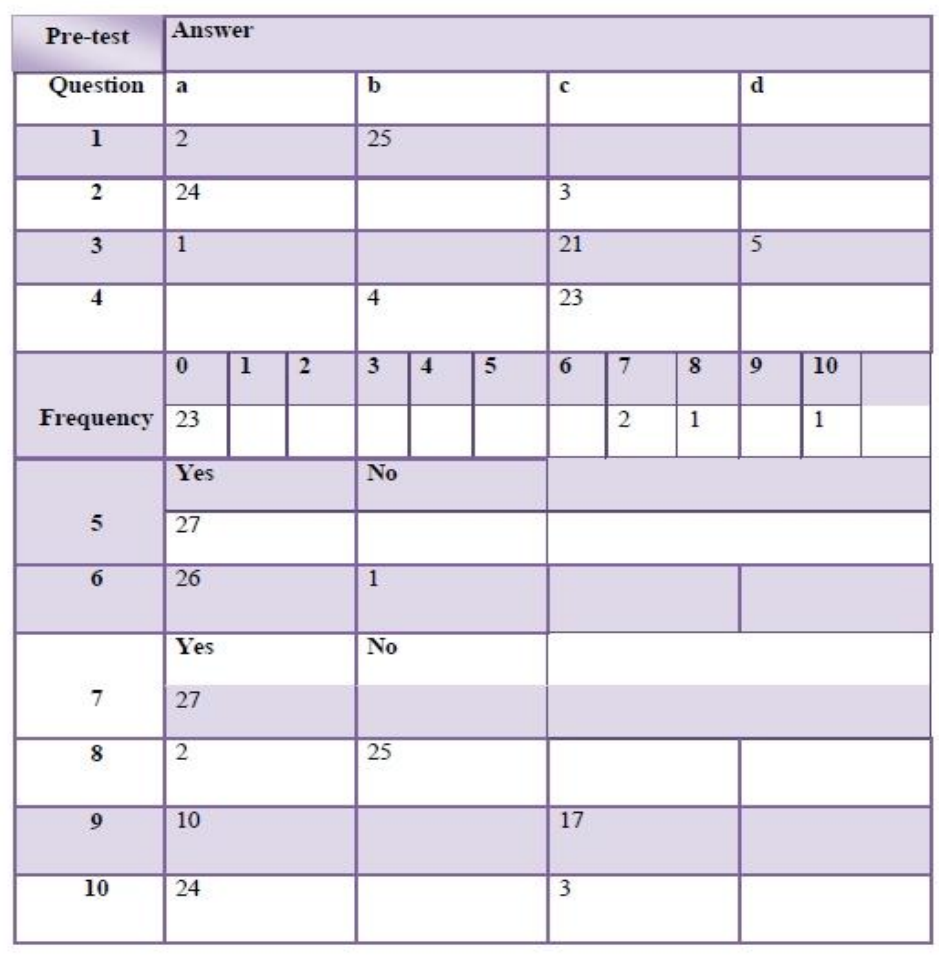

TABLE II.

Chart With The Results OF The Pre-Test In ESO 1

\begin{tabular}{|c|c|c|c|c|c|c|c|c|c|c|c|c|}
\hline \multicolumn{13}{|c|}{ Pre-test } \\
\hline \multicolumn{13}{|l|}{ Answer } \\
\hline Question & \multicolumn{3}{|l|}{ a } & \multicolumn{3}{|l|}{ b } & \multicolumn{3}{|l|}{ c } & \multicolumn{3}{|l|}{ d } \\
\hline 1 & \multicolumn{3}{|l|}{6} & \multicolumn{3}{|c|}{21} & & & & & & \\
\hline 2 & \multicolumn{3}{|l|}{17} & & & & \multicolumn{3}{|c|}{10} & & & \\
\hline 3 & \multicolumn{3}{|l|}{2} & & & & \multicolumn{3}{|c|}{21} & \multicolumn{3}{|l|}{4} \\
\hline 4 & \multicolumn{3}{|l|}{1} & \multicolumn{3}{|l|}{1} & \multicolumn{3}{|c|}{23} & \multicolumn{3}{|l|}{2} \\
\hline \multirow[b]{2}{*}{ Frequency } & 0 & 1 & 2 & 3 & 4 & 5 & 6 & 7 & 8 & 9 & 10 & \\
\hline & 23 & & 2 & & & & & & 1 & & 1 & \\
\hline & \multicolumn{3}{|c|}{ Yes } & \multicolumn{3}{|c|}{ No } & & & & \multicolumn{3}{|c|}{ ( } \\
\hline 5 & \multicolumn{3}{|l|}{24} & \multicolumn{3}{|l|}{3} & & & & & & \\
\hline 6 & \multicolumn{3}{|l|}{24} & \multicolumn{3}{|l|}{3} & & & & & & \\
\hline & \multicolumn{3}{|c|}{ Yes } & \multicolumn{3}{|c|}{ No } & & & & & & \\
\hline 7 & \multicolumn{3}{|l|}{26} & \multicolumn{3}{|l|}{1} & & & & & & \\
\hline 8 & \multicolumn{3}{|l|}{2} & 25 & & & & & & & & \\
\hline 9 & 8 & & & 2 & & & 17 & & & & & \\
\hline 10 & 19 & & & 4 & & & 4 & & & & & \\
\hline
\end{tabular}

Most students recognized perfectly well a case of bullying and they would act correctly in a situation of this type, that is, notifying to an adult. Moreover, as indicated before, almost all the students would like to feel the support of their peers if they suffered bullying so this shows signs of the success that this proposal could have.

Something that has called my attention in the negative sense is that in Primary 5, two students thought that the victims of bullying are always weird people. This indicates that we count on stereotypes and prejudices in the classroom; and the four cases of bullying that there seemed to be. (Martínez, 2016). Regarding ESO 1, the results which may sound concerning are the large number of students who would take a passive role as bystanders of bullying; those who think that shouting is a way of communicating; and those people who believe that if you reported bullying to adults, you 
would be a snitch. These results show that it is necessary an effective prevention program that leads students to a change of attitude.

On the other hand, in the post-test the number of students who suffered bullying passed from four to three people, in Primary 5, reducing thus the frequency (which went from 2 to 8) (Martínez, 2016). Something similar occurred in ESO 1 , where the two students who suffered bullying currently reduced the frequency of the harassment that they lived. Moreover, it was also reduced the number of people who thought that if you report a case of bullying, you would be a snitch; the number of bystanders that would remain passive in a bullying situation; and the students who thought that insulting and hitting were the best defense mechanisms that they could use when facing bullying. Therefore, it seems that this proposal has been effective to reduce bullying and victimization in the classroom and a great bullyingprevention tool in spite of its short implementation period. In addition, it is also a good tool to improve the English language level of the class as well as to use this language in real situations. Tables 3 and 4 reflect the results obtained in the realization of the post-test in Primary 5 (Martínez, 2016) and ESO 1.

TABLE III.

Chart With The Results Of The Post-Test In Primary 5 (MARTínez, 2016)

\begin{tabular}{|c|c|c|c|c|c|c|c|c|c|c|c|c|}
\hline Post-test & \multicolumn{12}{|c|}{ Answer } \\
\hline Question & \multicolumn{3}{|l|}{ a } & \multicolumn{3}{|l|}{ b } & \multicolumn{3}{|l|}{ c } & \multicolumn{3}{|l|}{ d } \\
\hline 1 & \multicolumn{3}{|l|}{1} & \multicolumn{3}{|c|}{26} & & & & & & \\
\hline 2 & \multicolumn{3}{|l|}{24} & & & & \multicolumn{3}{|l|}{3} & & & \\
\hline 3 & \multicolumn{3}{|l|}{1} & \multicolumn{3}{|l|}{2} & \multicolumn{3}{|c|}{19} & \multicolumn{3}{|l|}{5} \\
\hline 4 & \multicolumn{3}{|l|}{1} & \multicolumn{3}{|l|}{1} & \multicolumn{3}{|c|}{24} & \multicolumn{3}{|l|}{1} \\
\hline \multirow[b]{2}{*}{ Frequency } & 0 & 1 & 2 & 3 & 4 & 5 & 6 & 7 & 8 & 9 & 10 & \\
\hline & 24 & & 2 & & & & & & 1 & & & \\
\hline \multirow[b]{2}{*}{5} & \multicolumn{3}{|c|}{ Yes } & \multicolumn{3}{|c|}{ No } & & & & & & \\
\hline & \multicolumn{3}{|l|}{27} & \multicolumn{3}{|l|}{ 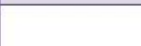 } & & & & & & \\
\hline 6 & \multicolumn{3}{|l|}{26} & \multicolumn{3}{|l|}{1} & & & & & & \\
\hline \multirow[b]{2}{*}{7} & \multicolumn{3}{|c|}{ Yes } & \multicolumn{3}{|c|}{ No } & & & & & & \\
\hline & \multicolumn{3}{|l|}{27} & & & & & & & & & \\
\hline 8 & \multicolumn{3}{|l|}{1} & \multicolumn{3}{|c|}{26} & & & & & & \\
\hline 9 & \multicolumn{3}{|l|}{5} & & & & \multicolumn{3}{|c|}{22} & & & \\
\hline 10 & \multicolumn{3}{|l|}{25} & & & & \multicolumn{3}{|l|}{2} & & & \\
\hline
\end{tabular}

TABLE IV.

Chart With The Results Of The Post-Test In ESO 1

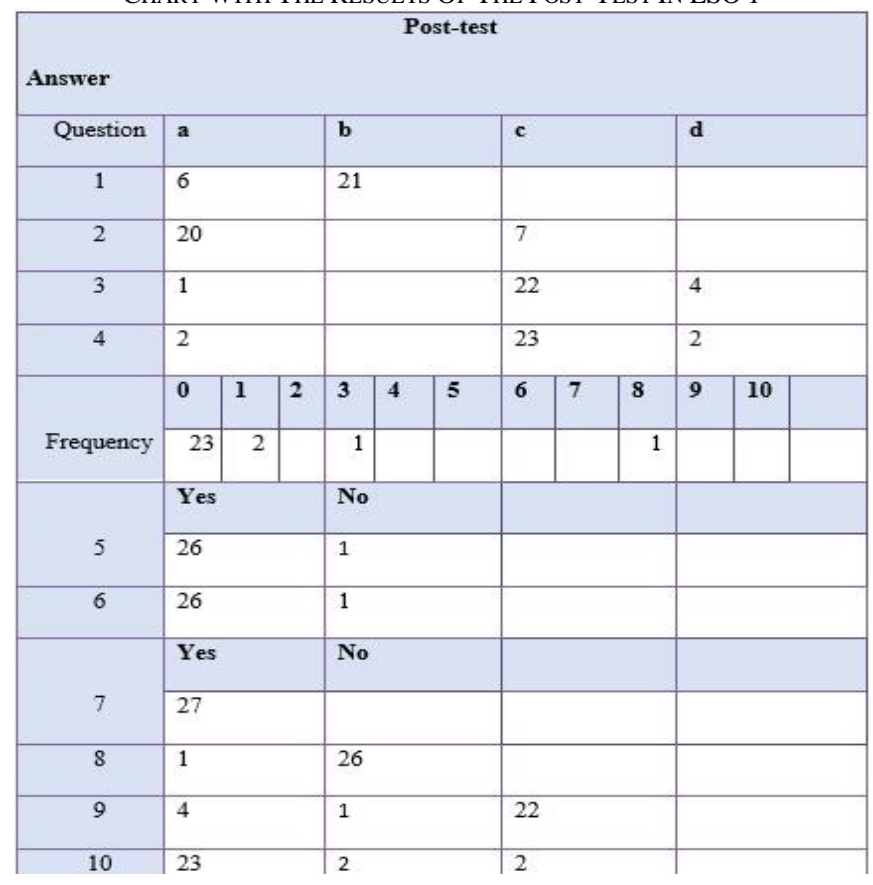


Fortunately, in both courses the number of students who thought that the victims of bullying are always weird people decreased after the implementation of this proposal, so thanks to this work some tags were removed. Moreover, the high number of people who felt fear in a situation of bullying as a bystander instead of bravery and willingness to help decreased too. That is, half of people who felt fear had changed for braver; so, all the talks and activities carried out have been profitable. With all this, it can be ensured that the proposal of this work has been effective and it has achieved a reduction in the number of bullying victims and an increment in the number of classmates that provide support to the victim making her/him more self-confident.

\section{CONCLUSIONS}

The present study shows a significant solution for bullying problems: increases the benefits of the KiVa project by complementing it with the benefits of the English language beyond its formal academic aspects. Furthermore, it fosters acceptance, cooperation, awareness and trust between pupils/students and adults and an interest in others. In addition, it gives the students the opportunity to situate themselves in terms of ethical and moral issues at the same time that they are able to build and strengthen their concept of community.

Regarding the first objective of this work, that is to explore the use of English as a Medium of Instruction (EMI) and communication to foster an appropriate atmosphere to develop an antibullying program, it was accomplished. A way of speaking English and improving the language without realizing it has been found by carrying out different suggested activities. At the same time, the goal of all the activities (apart from avoiding aggressive behaviour) was communication, so there was generated a base language for all the class members through which everybody communicated with everyone on equal terms. So, the objective of communicating in English in order to achieve an atmosphere of equality in the classroom has been reached thus suppressing group roles.

With regard to the second objective, that is to prevent bullying and reduce victimization by means of fostering an atmosphere of equality, respect and well-being in the classroom thanks to EMI and communication, it has also been accomplished. Bullying was reduced in an $18 \%$ of the cases and abolished in an $80 \%$. It has been shown that this proposal and its activities have led to an atmosphere of equality, respect, empathy and well-being in the classroom. Likewise, students' problem-solving skills increased, and through storytelling, they could gain valuable life lessons that will strengthen their sense of what it means to be vital and active community members.

As far as the third objective is concerned, that is to shed some light on the fact that the peers-bystanders' reaction is important when witnessing a case of bullying and thus, fostering a change in their attitude and transforming them into supporters of the victims, it has been fulfilled. The results suggest that the proposal prevents and counteracts bullying and victimization by means of influencing bystanders' attitudes in harassment situations, making them more valiant and eager to support the victim. Thereby, it is shown how important it is to receive support from the class group for both the victim and the bully. Thus, it ought to be used for benefiting the victims and increasing their self-confidence and for decreasing the alter ego of the bullies and making them humbler.

As a result of this proposal, students have been able to feel the warmth of their peers and it has been created a sense of togetherness beyond what the academic hours allow. Sometimes, this important part of cohabitation is neglected and all the importance is given to subjects, marks and homework. Sadly, we keep forgetting that none of this will work without the well-being of everyone in the classroom. Here, we talk about attitude, since our attitude determines our direction. So, if teachers want their students to finish the course, they should be concerned about their attitudes otherwise, their students will not reach the established goals and targets.

Finally, regarding the fourth objective, that is to contrast the results obtained in the Final Degree Dissertation and in the Final Master Dissertation in order to observe how bullying could be prevented depending on the educational stage of the student, I found that there are no-significant differences in the way of addressing bullying in such stages. The only one difference was found in how to work on ethos building depending on the age of the students. Older students needed activities more oriented to reflection in order to develop their critical thinking. On the other hand, younger students were more motivated with activities that implied physical movement. So, it gives us a clue about how to prevent bullying depending on the educational stage in which the implementation is carried out.

As far as drawbacks and limitations are concerned, it should be mentioned the short period of time aimed at the implementation of the proposal of this work (it would have to last an entire academic course at least, that is, 9 months). Despite the fact that there has been a small sample of students and not many cases of bullying, it can be said that positive results have been obtained for anti-bullying.

On the other hand, it should be remembered that the classroom is a changing stage where some unexpected events can happen at any moment and teachers ought to know how to face them. Fortunately, during this practice period I experienced different situations that have shaped me as a teacher and that will help me do my work better in the future. In addition, as tests show, apart from the peers' support, the attitude that the teacher takes in a conflict is very important for the victim. Therefore, future teachers should be very careful with the way they act to be knowledgeable about what bullying is and to be alert if they see signs of it in the classroom. Moreover, they must provide support to the victims and have frequent tutorials with bullies, victims and bystanders since, as this study shows, some dedication and attention by the teacher can get very favourable results in reducing bullying. 
A teacher is not only someone who transmits knowledge, but someone who educates the soul. Thus, this study leaves the door open to further investigations into what way the teacher's attitude could be beneficial or harmful in bullying situations. Without forgetting, of course, the contributions of this proposal regarding the benefits of the peer group support in a bullying situation and the English language as an equality element, that is to say, as a tool to suppress and to avoid group roles. There is still much to do with regard to this theme so, we hope that this work could be useful as a motivation for future research. And also, that the very positive results obtained in such a short period of time encourage us to continue working and fighting against bullying and make us think about how great would be the benefits for the students if the proposal was implemented from the beginning of the course and during several academic years. It seems that the basis of the KiVa project and the English language as a tool to promote equality in the classroom form a good combination that leads to very favourable results in fighting against bullying in the school.

Through this work and its investigation process we have learned two main things: the first one concerns the students involved in a conflict of bullying, for them it is very important to have the support of their classmates and feeling that they are not alone. Moreover, through the proposed activities and a methodology based on reflection and communication students perceive a real group feeling and they know the great value of empathy, respect and equality. The second thing is related to Paulo Freire's words: "Education does not change the world. It changes people that will change the world", and our world needs a real change so that humans could be more human and conflicts such as bullying will not be the cause of suicides anymore, depressions and the loss of smiles. What would life be if we had no courage to attempt anything new? We can make it happen.

\section{ACKNOWLEDGMENTS}

The authors wish to thank the University of Turku for all the information sent about KiVa in an altruistic way since it was very helpful during the documentation stage. In the same way, the authors wish to thank El Armelar School and Mercurio School for the collaboration provided in the implementation of this project.

\section{REFERENCES}

[1] Athola, A., Haataja, A., Salmivalli, C. and Poskiparta, E. (2012). For children only? Effects of the KiVa antibullying program on teachers. Teaching and Teacher Education, 28, 851-859.

[2] Card, N., and Hodges, E. (2008). Peer Victimization among Schoolchildren: Causes, Consequences, and Considerations in Assessment and Intervention. School Psychology Quarterly, 23, 451-461.

[3] Dearden, J. (2015). English as a medium of instruction - a growing global phenomenon, 4-28. Retrieved from https://www.britishcouncil.org/sites/default/files/e484_emi_-_cover_option_3_final_web.pdf (accessed 1/11/2017).

[4] Del Barrio, C. et al. (2011). Contribuyendo al bienestar emocional de los compañeros: evaluación del Programa Compañeros Ayudantes en un instituto madrileño. European Journal of Education and Psycholgy, 4(1), 5-17.

[5] Elder, D. and Hoylan, R. (2010). Life Lessons through Storytelling: Children's Exploration of Ethics. Journal of Folklore Research Reviews, 1, 1-2.

[6] European Commission. (2009). Compendium: Study on the Contribution of Multilingualism to Creativity. Compendium Part One: Multilingualism and Creativity: Towards an Evidence-base. Brussels: European Commission, 1-17.

[7] Gordon, M. and Spilsbury, L. (2014). Say no to bullying. Hauppauge, NY: Barron's Educational Series, Inc.

[8] Hawker, D., and Boulton, M. (2000). Twenty Years' Research on Peer Victimization and Psychosocial Maladjustment: A Meta-Analytic Review of Cross-Sectional Studies. Journal of Child Psychology and Psychiatry, 41, 441-455.

[9] Haynie, D., Nansel, T., Eitel, P., Crump, A., Saylor, K., Yu, K. and Simons-Morton, B. (2001). Bullies, victims, and bullyvictims: Distinct groups of at-risk youth. Journal of Erly Adolescence, 21, 29-49.

[10] Herkama, S. (2012). KiVa Anti-bullying program: Program contents and evidence of effectiveness. Solutions for safe and respectful schools. Latvia, 16-18.

[11] Kristo, A. (2010). The Importance of Learning English at an Early Age. Retrieved from http://azilleokristomozihim.blogspot.com.es/2010/11/importance-of-learning-english-at-early.html (accessed 1/11/2017).

[12] Martínez, M. (2016). The class group attitude and the English language: a perfect combination to reduce bullying problems in the classroom (Final Degree Project). Facultad de Magisterio, Universidad de Valencia, Valencia.

[13] Mavroudis, N. and Bounelli, P. (2016). The role of drama in education counteracting bullying in schools. Cogent education, 3, $1-2$.

[14] Mochizuki, K. (1993). Baseball Saved Us. New York: Lee \& Low.

[15] Mydans, S. (April 9, 2007). Across cultures, English is the word! The New York Times. Retrieved from http://www.nytimes.com/2007/04/09/world/asia/09iht-englede.1.5198685.html?_r=0 (accessed 1/11/2017).

[16] Pavesi, M., Bertocchi, D., Hofmannová, M., and Kazianka, M. (2001). Teaching through a Foreign Language. Retrieved from http://www.ub.edu/filoan/CLIL/teachers.pdf (accessed 1/11/2017).

[17] Rivers, I., et al. (2009). Observing Bullying at School: The Mental Health Implications of Witness Status. School Psychology Quarterly, 24, 211-223.

[18] Sainio, M., Veenstra, R., Huitsing, G.; and Salmivalli, C. (2011). Victims and their defenders: A dyadic approach. International Journal of Behavioral Development, 35, 144-151.

[19] Salmivalli, C., Lagerspetz, K., Björkqvist, K., Österman, K., and Kaukiainen, A. (1996). Bullying as a group process: Participant roles and their relations to social status within the group. Aggressive Behavior, 22(1), 1-15.

[20] Salmivalli, C. (2010). Bullying and the Peer Group: A Review. Aggression and Violent Behavior, 15, 112-120. 
[21] Salmivalli, C., Kärnä, A., and Poskiparta, E. (2011). Counteracting bullying in Finland: The KiVa program and its effects on different forms of being bullied. International Journal for Behavioral Development, 35(5), 405-411.

[22] Salmivalli, C., Kärna, A., Poskiparta, E., Little, T.D., Kaljonen, A., and Voeten, M. (2011). A large-scale evaluation of the KiVa anti-bullying program: grades 4-6. Child Development, 82(1), 311-330.

[23] Salmivalli, C., and Poskiparta, E. (2012). Making bullying prevention a priority in Finnish schools: The KiVa anti-bullying program. New Directions For Youth Development, 133(4), 41-53.

[24] Salmivalli, C., Garandeau, C.F., and Lee, I.A. (2016). Decreases in the proportion of bullying victims in the classroom: Effects on the adjustment of remaining victims. International Journal of Behavioral Development. Advance online publication. doi:10.1177/0165025416667492.

[25] Simons, F., and Charles, F. (2017). Languages of the World. Ethnologue, 1 (20). Retrieved from http://www.ethnologue.com (accessed 1/11/2017).

[26] Sourander, A., et al. (2007). What is the Early Adulthood Outcome of Boys Who Bully or Are Bullied in Childhood? The Finnish "From a Boy to a Man" Study. Pediatrics, 120, 397-404.

[27] Wentzel, K. (2009). Peers and academic functioning at school. Handbook of peer interactions, relationships, and groups, 531547, New York: Guilford.

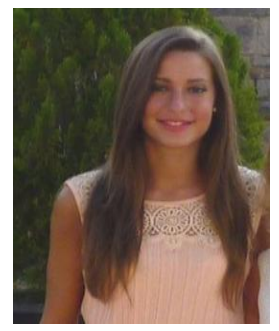

María de la Hoz Martínez Jiménez Born in Valencia in 1994. Student of La Salle School and the University of Valencia. Primary Teacher Degree (English major) by the University of Valencia, Spain (2016) and Master in Secondary Education (English major) by the aforementioned university (2017). Currently studying a PhD of Education in the University of Valencia, Spain.

She worked as a teacher in an English academy during two years and currently, she is a teacher in La Salle School in Paterna, Valencia (Spain). Moreover, she gives private lessons and is hostess of congresses and events in Valencia, Spain. Regarding her research interests, she is major in bullying programs and she has already written a project about it: Martínez, M. (2016). The class group attitude and the English language: a perfect combination to reduce bullying problems in the classroom (Final Degree Project). Facultad de Magisterio, Universidad de Valencia, Valencia.

Mss. Martínez is currently a member of the TALIS Research Group in the University of Valencia, Spain; and she was awarded honors when she finished the High School.

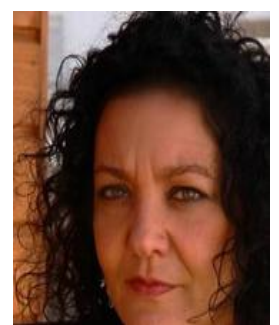

María Alcantud Díaz was born in Cartagena in 1967. She received her PhD in English Philology from Universitat de València, Valencia, Spain in 2011. A strong advocate of hands-on, learning-by doing education, she involves her students in a variety of Service Learning, literary, multilingual and technology-infused activities that provide them with opportunities to use their English to share intercultural knowledge. She is currently teaching English Language (last year of the Primary Teacher of English Degree) and Learning and Teaching Foreign Languages (in the Master of Secondary Education) at the Faculty of Education in Valencia, Spain (Didactics of Language and Literature, English area). Her last publication is: Service-Learning and Project TALIS. Pedagogy and Teaching Destined to Mutual Understanding. Pedagogika (2017).

Dr. Alcantud is the Director of the Project Talis Research Group (www.proyectotalis.com). She belongs to AESLA, AEDEAN and SEDLL. In 2017 she was awarded with the first prize of the Motivem with Students contest at her University. 